\title{
Impact of diurnal temperature variations on hospitalization due to cardiovascular and respiratory diseases in Rafsanjan, Iran, in 2008-2013
}

\author{
Hassanlouei B, $\mathrm{MSc}^{1}$, Rezaeian M, $\mathrm{PhD}^{2}$, Sheikh-Fathollahi M, $\mathrm{PhD}^{3}$, Vazirinejad $\mathrm{R}, \mathrm{PhD}^{* 4}$ \\ 1- Researcher, Solid Tumor Research Center, Urmia University of Medical Science, Urmia, Iran. 2- Professor, Epidemiologist, \\ Dept. of Social Medicine, Occupational Environmental Research Center, Rafsanjan Medical School, Rafsanjan University of \\ Medical Sciences, Rafsanjan, Iran. 3- Assistant Prof., Dept. of Social Medicine, Rafsanjan University of Medical Sciences, \\ Rafsanjan, Iran 4- Professor, Dept. of Social Medicine, Rafsanjan University of Medical Sciences, Rafsanjan, Iran.
}

Received: December 2014, Accepted: February 2015

Background: Changes in global temperature and its health effects have recently been under much investigated. Consequently, these changes have affected mortality and morbidity rates which are important public health indices. The present study examines the effect of mean temperature on the frequency of hospitalization due to cardiovascular and respiratory diseases in Ali Ibn Abi Talib Hospital of Rafsanjan, Iran.

Materials and Methods: In this ecological study, data on hospitalization were gathered from electronic systems of hospitals and the data from the weather organizations were extracted from the weather station. All patients not living in Rafsanjan were excluded. Data were entered into SPSS and SAS software and the association between mean temperature and hospitalization frequency were analyzed using Poisson regression models.

Results: A negative significant association was found between mean temperature and mean number of hospitalizations due to cardiovascular and respiratory diseases. By each $1{ }^{\circ} \mathrm{C}$ decrease in mean temperature, the mean number of hospitalizations due to cardiovascular and respiratory diseases increased by $1 \%(95 \% \mathrm{CI} ; 0.63-1.26 \%)$ and $4.33 \%$ (95\% CI; 4-4.64\%), respectively. For cardiovascular diseases, there was no significant difference in mean number of admissions based on different age groups. However, in the 0-4-year age group, the mean number of hospitalizations due to respiratory diseases was significantly higher than the other age groups. For both cardiovascular and respiratory diseases, there was no significant difference between females and males in terms of the mean number of hospitalizations.

Conclusions: Reduction in mean temperature, in the present study, increased the mean number of hospitalizations due to cardiovascular and respiratory diseases and it was stronger for respiratory diseases. According to these findings, people who are at risk of cardiovascular and respiratory diseases should be forbidden from exposure to extremely cold temperatures.

Keywords: Temperature, Cardiovascular Diseases, Respiratory Diseases, Iran

\section{Introduction}

Recently, there has been an increasing trend in public concerns about changes in the Earth's environment and its effects on human health (1, 2). During the past century, the average surface temperature of the Earth has increased at the rate of $2{ }^{\circ} \mathrm{C}$ secure threshold (1). One of the harmful effects of ambient temperature changes is its impact on the increase in disease burden that is very important from the perspective of public health (3-7). The World Health Organization (WHO) has estimated more than 150,000 deaths per year due to the impact of these changes for the past three decades (8). Many previous and recent studies have shown that cold and warm ambient temperatures are relevant to increased

\footnotetext{
* Corresponding author: Reza Vazirinejad, Dept. of Social Medicine, Rafsanjan University of Medical Sciences, Rafsanjan, Iran.

Email: rvazirinejad@yahoo.co.uk
} 
risk of cardiovascular diseases and respiratory morbidity (6, 9-23). Moreover, in many countries, a survey of hospitalization and emergency data has shown that ambient temperature variations affect the number and type of hospitalized patients (24-28).

More studies on the effects of ambient temperature on cardiovascular and respiratory diseases morbidity have been conducted in developed countries that have cold weather such as North American and European counties (4). Furthermore, few studies have been conducted in developing countries such as Iran that mostly have tropical and subtropical climates. Review of literature revealed that ambient temperature in different parts of the world has different effects on the occurrence of these two important groups of diseases and the obtained results of different countries and diverse research proposals have not required homogeneity for overall decision making of all climate zones of world $(4,29,30)$. Thus, the aim of the present study was to investigate the effect of temperature on the frequency of hospitalization due to respiratory and cardiovascular diseases in Ali Ibn Abi Talib (pbh) Hospital in Rafsanjan, Iran, from 2008 to 2013.

\section{Materials and Methods}

This was an ecological study. The studied samples included all patients hospitalized due to cardiovascular (I00-I55) and respiratory diseases (J00-J99) in Ali Ibn Abi Talib (pbh) Hospital in Rafsanjan from April 1, 2008 to January 30, 2013.

All admitted patients who were not inhabitants of one of the villages or towns of Rafsanjan or were referred from another town to Ali Ibn Abi Talib (pbh) Hospital were excluded from this study. Information about the climate and its changes were extracted from the weather bureau stations of Rafsanjan. It should be noted that the samples were divided into 6 age groups of $0-4$, $5-14,15-64,65-74,75-79$, and 80 years and higher (according to previous studies and conventional medical divisions) to determine the exact effect of age. The collected data were coded and entered into SPSS software (version 21.0; SPSS Inc., Chicago, IL, USA) and SAS software (version 9.1; SAS Institute, Cary, NC, USA). The applied statistical model was the generalized linear model (GLM).

\section{Results}

Age and sex distribution of patients hospitalized due to cardiovascular and respiratory diseases has been presented in table 1. Most previous studies have examined only special subgroups of these two groups of studied patients (4).

Table 1: Age and sex distribution of those hospitalized due to cardiovascular and respiratory diseases (group and subgroup)

\begin{tabular}{ccccc}
\hline \multirow{2}{*}{ Disease Group } & \multicolumn{2}{c}{ Cardiovascular } & \multicolumn{2}{c}{ Respiratory } \\
\cline { 2 - 4 } Age Group & Male & Female & Male & Female \\
\cline { 2 - 4 } $\mathbf{0 - 4}$ & $31(0.6 \%)$ & $37(0.8 \%)$ & $927(20.2 \%)$ & $647(16.1 \%)$ \\
\hline $\mathbf{5 - 1 4}$ & $16(0.3 \%)$ & $13(0.3 \%)$ & $250(5.5 \%)$ & $190(4.7 \%)$ \\
\hline $\mathbf{1 5 - 6 4}$ & $3117(62 \%)$ & $2223(48.9 \%)$ & $1703(37.2 \%)$ & $1679(41.8 \%)$ \\
\hline $\mathbf{6 5 - 7 4}$ & $915(17.9 \%)$ & $1106(13.3 \%)$ & $626(13.7 \%)$ & $543(13.5 \%)$ \\
\hline $\mathbf{7 5 - 7 9}$ & $473(9.3 \%)$ & $606(13.3 \%)$ & $423(9.2 \%)$ & $386(9.6 \%)$ \\
\hline $\mathbf{8 0}$ and higher & $506(9.9 \%)$ & $562(12.4 \%)$ & $650(14.2 \%)$ & $573(14.3 \%)$ \\
\hline Total & $5112(100 \%)$ & $4547(100 \%)$ & $4579(100 \%)$ & $4018(100 \%)$ \\
\hline
\end{tabular}


Table 2: Percent change of hospitalization due to cardiovascular and respiratory diseases associated with a $1^{\circ} \mathrm{C}$ variation

\begin{tabular}{lcc}
\hline & \% change $(\mathbf{9 5 \%}$ CI) & P \\
\hline Total Cardiovascular & $-1.00(-1.26$ to -0.63$)$ & $<0.001$ \\
\hline Angina pectoris & $-0.73(-1.41$ to -0.05$)$ & 0.0335 \\
\hline $\begin{array}{l}\text { Acute myocardial } \\
\text { infarction }\end{array}$ & $-0.83(-1.842$ to 0.20$)$ & 0.1128 \\
\hline Ischemic heart disease & $-0.59(-1.10$ to -0.08$)$ & 0.0242 \\
\hline Heart failure & $-2.56(-3.58$ to -1.53$)$ & $<0.001$ \\
\hline Total respiratory & $-4.34(-4.64$ to -4.02$)$ & $<0.001$ \\
\hline Asthma & $-3.78(-4.93$ to -2.63$)$ & $<0.001$ \\
\hline Influenza and pneumonia & $-5.47(-5.97$ to -4.97$)$ & $<0.001$ \\
\hline
\end{tabular}

However, a number of studies have examined important subgroups in addition to main groups $(22,29)$. In this study, the fitness results of the regression model have been presented for both gropes of cardiovascular and respiratory diseases, and for important subgroups. These results are shown in table 2 .

Table 3: Percent change of hospitalization due to cardiovascular and respiratory diseases in males and females associated with a $1^{\circ} \mathrm{C}$ variation

\begin{tabular}{ccccc}
\hline & \multicolumn{2}{c}{ Total cardiovascular } & \multicolumn{2}{c}{ Total respiratory } \\
\cline { 2 - 6 } & \% change $(\mathbf{9 5 \%}$ CI) & P-Value & \% change $(\mathbf{9 5 \%}$ CI) & P \\
\cline { 2 - 6 } Male & $-1.26(-1.69$ to -0.84$)$ & $<0.001$ & $-4.47(-4.89$ to -4.05$)$ & $<0.001$ \\
\hline Female & $-0.58(-1.04$ to -0.11$)$ & 0.0155 & $-4.17(-4.62$ to -3.71$)$ & $<0.001$ \\
\hline
\end{tabular}

In addition, to clarify the influence of important modifiers such as age and sex, the fitness results of the regression model are shown in tables 3 and 4 . The presented results in tables 1 to 4 indicate that mean temperature has an inverse relationship with mean number of cardiovascular and respiratory diseases.

Table 4: Percent change of hospitalization due to cardiovascular and respiratory diseases in age groups associated with a $1^{\circ} \mathrm{C}$ variation

\begin{tabular}{ccccc}
\hline & \multicolumn{2}{c}{ Total cardiovascular } & \multicolumn{2}{c}{ Total respiratory } \\
\cline { 2 - 5 } & \% change $(\mathbf{9 5 \%} \mathbf{C I})$ & P-Value & \% change $(\mathbf{9 5 \%} \mathbf{C I})$ & P \\
\hline $\mathbf{0 - 4}$ & $*$ & $*$ & $-9.9(-10.59$ to -9.21$)$ & $<0.001$ \\
\hline $\mathbf{5 - 1 4}$ & $*$ & $*$ & $-5.61(-6.97$ to -4.22$)$ & $<0.001$ \\
\hline $\mathbf{1 5 - 6 4}$ & $-1.03(-1.44$ to -0.6$)$ & $<0.001$ & $-3.10(-3.60$ to -2.59$)$ & $<0.001$ \\
\hline $\mathbf{6 5 - 7 4}$ & $-0.46(-1.16$ to 0.24$)$ & 0.1959 & $-3.02(-3.90$ to -2.14$)$ & $<0.001$ \\
\hline $\mathbf{7 5 - 7 9}$ & $-1.02(-1.94$ to -0.08$)$ & 0.0325 & $-2.61(-3.51$ to -1.98$)$ & $<0.001$ \\
\hline $\mathbf{8 0}$ and higher & $-1.42(-2.35$ to -0.47$)$ & 0.0033 & $-2.57(-3.40$ to -1.73$)$ & $<0.001$ \\
\hline
\end{tabular}

* Because of shortage of hospitalization number the model fitting was not possible 


\section{Discussion}

\section{Cardiovascular diseases}

The obtained results of this research showed that cold weather can cause an increased risk of hospitalization due to cardiovascular diseases in this region. In a study conducted in Copenhagen, Denmark, it was observed that cardiovascular disease is inversely related to temperature (30). In another study conducted in Shanghai, China, similar results were obtained (7). The mechanism of cold temperature in increasing the risk of cardiovascular diseases is still unclear (31). However, several risk factors, such as plasma cholesterol, plasma fibrinogen, blood pressure, and red and white blood cell count, can partially explain this mechanism (30). The study by Michelozzi et al., which examined the relationship between temperature and hospitalizations due to cardiovascular disease in 12 different countries in Europe, showed that temperature has a direct relationship with the hospitalization due to cardiovascular diseases (29). This finding was not in agreement with the results of the present study. Furthermore, the results of this study were consistent with that of the study performed in Beijing (32). Investigation of the relationship between temperature and daily hospitalization rate due to cardiovascular disease in the 4 major cities of South Korea showed that daily ambient temperature increased hospitalizations rate for this group of patients (22). The results of this study are consistent with the results of the present study. The main mechanism of the adverse effects of high temperatures may through the blood circulation system of the human body heat in regulating body temperature, when the layers beneath the skin send blood to the vital organs. It also increases blood viscosity due to diarrhea, excessive sweating, and increased cholesterol levels; other possible mechanisms can also be considered $(15,33)$.The age-adjusted relationship (one of the most important predictors) between temperature and the mean number of hospitalizations was evaluated in this study. The results of this study suggest that there is no significant difference among different age groups in hospitalization due to cardiovascular disease. A study in Denmark showed no differences among age groups of patients (30). These results were consistent with our findings. The findings of other studies in China, South Korea, and America showed that patients older than 70 years were significantly lower compared with other age groups $(22,32,34)$. These findings were consistent with the results of the present study. Elderly patients' weak physiological systems and inability in environmental adaptation are some of the factors that causes sensitivity to drastic ambient temperature changes and increased hospitalization in this age group $(15$, 20, 35-39). Gender is another deflator which was examined. The results showed no significant difference between males and females in terms of the mean number of hospitalizations due to cardiovascular disease. These results were consistent with findings from studies in America, England, and France (40-42). However, another study showed higher risk of coronary events in women than in men in hot weather (43). These results are consistent with the findings of the present study.

Many studies have evaluated cardiovascular diseases as their major groups (4). This study also examined the major categories of cardiovascular disease. In this study, the relationship between mean temperature and mean number of hospitalizations due to acute myocardial infarction was not significant. This is consistent with the results found in the literature review. The obtained results from myocardial infarction patients in Melbourne, Australia, showed that the number of hospitalizations due to this disease increases with the decreasing of temperature (44). In this regard, studies in Taiwan, Germany, the UK, and Norway have also been obtained (45-48). The results of another study conducted in the UK, were contradictory to the mentioned studies. In this study, it was shown that hospitalization due to acute myocardial 
infarction significantly increased as a result of the increase in temperature (49). The heterogeneity in results may be described in any particular area of environment (45).

Another important subgroup of cardiovascular diseases is angina pectoris, which was examined in this study. The results showed that the mean temperature decreases hospitalization. A study in California, USA, showed that the decline in temperature causes an increase in the minimum threshold for hospitalization due to angina pectoris (34). This finding was in agreement with the results of the present study. Ischemic heart disease and other cardiovascular diseases are subgroups of the main studied groups. The results showed a relationship between the average number of patients and mean temperature. This is consistent with the results obtained from literature review. Survey data obtained in California, USA, in terms of hospitalization showed a direct relationship between temperature and mean number of hospitalizations due to strokes (20). The last group of cardiovascular disease that was studied had heart failure results of studies in South Korea and was consistent with another study in America $(22,50)$. In the present study, mean temperature was found to be inversely related to mean number of hospitalizations due to this disease. The literature review showed that previous study results are consistent with the findings of the present study. A study in the state of New York, USA, showed that there is a direct relationship between temperature and hospitalizations due to heart failure (51). These results are consistent with findings of studies conducted by Green et al. and Ostro et al. $(20,50)$.

\section{Respiratory disease}

The results showed that mean temperature is inversely related to hospitalization due to respiratory diseases. A study conducted in Finland, in 2009, showed that temperature and hospitalization due to respiratory diseases have a significant relationship (52). These results were consistent with the findings of the studies performed in Shanghai, China, and Taiwan (7, 28). A study conducted in 12 cities in Europe yielded mixed results. The study findings highlight the fact that the rate of hospitalization due to respiratory disease increases with the increasing of temperature (29). These results were also reported by Ostro et al., Lin et al., Green et al., and Wang et al. $(20,32,50,53)$. It should be noted that the exact mechanism of hot and cold ambient temperatures on physiological systems remains unknown. These diseases may be directly caused by inflammation of airway responsiveness due to temperature or indirectly by viral infections, pollens, air pollution, mold, number of hours spent outdoors, and activities that aggravate the disease $(22,26,54)$. The results for different age groups showed that the rate of hospitalization due to respiratory disease is significantly higher in the 0-4-year age group than other age groups. These results were consistent with the findings of a study conducted in the USA in 2007 (55). In addition, another study in Europe showed that a significantly higher number of patients in the age group of higher than 75 years were hospitalized (29). These findings were consistent with that of the present study.

The results of this study showed no significant difference in the mean number of hospitalizations due to respiratory disease between the sexes. In literature review, no study was found to consider differences among sexes. Asthma is one of the most common types of respiratory diseases that were examined in this study. Results of this study show that with increasing temperature, the mean number of hospitalizations due to this disease significantly reduced. These findings were consistent with the results of studies conducted in Greece and Finland $(52,56)$. In two studies in the states of North Carolina and New York in the USA, a direct relationship was observed between rising temperatures and increased hospitalization due to this disease $(26,51)$. These results were consistent with the results of our study. Pneumonia and influenza 
are other respiratory diseases that are among the major groups studied. The findings of this study showed that the mean number of hospitalizations due to these conditions is related to average temperatures. The results of this study were consistent with that of two studies performed in China and Taiwan (28, 57). These results were also consistent with findings of the present study. Cold weather increases population density and reduces air conditioning and this may cause infectious diseases, and pneumonia and influenza by direct contact transmission $(20,50)$. The results of studies that examined the relationship between ambient temperature and hospitalizations due to cardiovascular and respiratory diseases with different designs and in different countries and cities were not homogeneous. This may be because people in different parts of the world may not have the same tolerance level to certain climates that have adapted their residences (45). Aside from the mentioned geographic heterogeneity of studies, examining the relationship between temperature and hospitalizations due to cardiovascular and respiratory diseases, there are other factors that can be effective in this heterogeneity. For example, the probability of acceptance for a particular disease may be have different reasons such as the availability of primary care, outpatient services for patients, community care area level socioeconomic deprivation, and community associated clinical management (29).

\section{Conclusions}

Our study showed that reduction in mean temperature has been associated with increasing the mean number of hospitalizations due to cardiovascular and respiratory diseases. This association was very strong for respiratory diseases compared to for cardiovascular diseases. According to our findings, people who suffer from cardiovascular and respiratory diseases should be forbidden from exposure to extremely cold temperatures. In case of as a significant reduction in environment temperatures the health system should warn at risk people and children's.

\section{Acknowledgement}

We would like thank Rafsanjan University of Medical Sciences for their cooperation in carrying out this research.

Conflict of interests: None declared.

\section{Reference}

1. Costello A, Abbas M, Allen A, Ball S, Bell S, Bellamy R, et al. Managing the health effects of climate change: Lancet and University College London Institute for Global Health Commission. Lancet 2009; 373(9676):1693733.

2. McMichael AJ, Butler CD. Promoting global population health while constraining the environmental footprint. Annu Rev Public Health 2011; 32:179-97.

3. Medina-Ramón M, Schwartz J. Temperature, temperature extremes, and mortality: a study of acclimatisation and effect modification in 50 US cities. Occup Environ Med 2007; 64(12):827-33.

4. Turner LR, Barnett AG, Connell D, Tong S. Ambient Temperature and Cardiorespiratory Morbidity: A Systematic Review and Metaanalysis. Epidemiology 2012; 23(4):594-606.

5. McGill DJ, Mackay IR. The effect of ambient temperature on capillary vascular malformations. $\mathrm{Br}$ J Dermatol 2006; 154(5):896-903.

6. Chung JY, Honda Y, Hong YC, Pan XC, Guo YL, Kim H. Ambient temperature and mortality: An international study in four capital cities of East Asia. Sci Total Environ 2009; 408(2):390-6.

7. Ma W, Xu X, Peng L, Kan H. Impact of extreme temperature on hospital admission in Shanghai, China. Sci Total Environ 2011; 409(19):3634-7.

8. Patz JA, Campbell-Lendrum D, Holloway T, Foley JA. Impact of regional climate change on human health. Nature 2005; 438(7066):310-7.

9. Bean WB, Mills CA. Coronary occlusion, heart failure, and environmental temperatures. Am Heart J 1938; 16(6):701-13.

10. Halonen JI, Zanobetti A, Sparrow D, Vokonas PS, Schwartz J. Outdoor temperature is associated with serum HDL and LDL. Environ Res 2011; 111(2):281-7.

11. Basu R, Malig B. High ambient temperature and mortality in California: Exploring the roles of age, disease, and mortality displacement. Environ Res 2011; 111(8):1286-92. 
12. Ren C, O'Neill MS, Park SK, Sparrow D, Vokonas P, Schwartz J. Ambient temperature, air pollution, and heart rate variability in an aging population. Am $\mathrm{J}$ epidemiol 2011;173(9):1013-21.

13. McMichael AJ, Wilkinson P, Kovats RS, Pattenden S, Hajat S, Armstrong B, et al. International study of temperature, heat and urban mortality: the 'ISOTHURM' project. Int J Epidemiol 2008; 37(5):1121-31.

14. Ostro BD, Roth LA, Green RS, Basu R. Estimating the mortality effect of the July 2006 California heat wave. Environ Res 2009; 109(5):614-9.

15. Basu R. High ambient temperature and mortality: a review of epidemiologic studies from 2001 to 2008. Environ Health 2009; 8(1):40.

16. Pudpong N, Hajat S. High temperature effects on out-patient visits and hospital admissions in Chiang Mai, Thailand. Sci Total Environ 2011; 409(24):5260-7.

17. Kendrovski VT. The impact of ambient temperature on mortality among the urban population in Skopje, Macedonia during the period 1996-2000. BMC Public Health 2006; 6(1):44.

18. Cheng X, Su H. Effects of climatic temperature stress on cardiovascular diseases. Eur J Intern Med 2010; 21(3):164-7.

19. Schneider A, Panagiotakos D, Picciotto S, Katsouyanni K, Löwel H, Jacquemin B, et al. Air temperature and inflammatory responses in myocardial infarction survivors. Epidemiology 2008; 19(3):391-400.

20. Green RS, Basu R, Malig B, Broadwin R, Kim JJ, Ostro B. The effect of temperature on hospital admissions in nine California counties. Int J Public Health 2010; 55(2):113-21.

21. Fuster V, Kelly BB. Promoting Cardiovascular Health in the Developing World: A Critical Challenge to Achieve Global Health. Washington (DC): National Academies Press 2010.

22. Lim YH, Hong YC, Kim H. Effects of diurnal temperature range on cardiovascular and respiratory hospital admissions in Korea. Sci Total Environ 2012; 417-418:55-60.

23. Lin S, Hsu WH, Van Zutphen AR, Saha S, Luber G, Hwang SA. Excessive heat and respiratory hospitalizations in New York State: Estimating current and future public health burden related to climate change. Environ health perspect 2012; 120(11):1571-7.

24. Liang WM, Liu WP, Chou SY, Kuo HW. Ambient temperature and emergency room admissions for acute coronary syndrome in Taiwan. Int J Biometeorol 2008; 52(3):223-9.

25. Knowlton K, Rotkin-Ellman M, King G, Margolis HG, Smith D, Solomon G, et al. The 2006 California heat wave: impacts on hospitalizations and emergency department visits. Environ health perspect 2009; 117(1):61-7.

26. Buckley JP, Richardson DB. Seasonal modification of the association between temperature and adult emergency department visits for asthma: a case-crossover study. Environ Health 2012; 11(1):55.

27. Turner LR, Connell D, Tong S. Exposure to hot and cold temperatures and ambulance attendances in Brisbane, Australia: a timeseries study. BMJ open 2012; 2(4).

28. Wang YC, Lin YK, Chuang CY, Li MH, Chou $\mathrm{CH}$, Liao $\mathrm{CH}$, et al. Associating emergency room visits with first and prolonged extreme temperature event in Taiwan: a populationbased cohort study. Sci Total Environ 2012; 416:97-104.

29. Michelozzi P, Accetta G, De Sario M, D'Ippoliti D, Marino C, Baccini M, et al. High temperature and hospitalizations for cardiovascular and respiratory causes in 12 European cities. Am J Respir Critl Care Med 2009; 179(5):383-9.

30. Wichmann J, Andersen Z, Ketzel M, Ellermann T, Loft S. Apparent temperature and causespecific emergency hospital admissions in Greater Copenhagen, Denmark. PloS One 2011; 6(7):e22904.

31. Mercer JB. Cold-an underrated risk factor for health. Environ Res 2003; 92(1):8-13.

32. Wang MZ, Zheng S, He SL, Li B, Teng HJ, Wang SG, et al. The association between diurnal temperature range and emergency room admissions for cardiovascular, respiratory, digestive and genitourinary disease among the elderly: A time series study. Sci Total Environ 2013; 456-457:370-5.

33. Kovats RS, Hajat S. Heat stress and public health: a critical review. Annu Rev Public Health 2008; 29:41-55.

34. Ebi KL, Exuzides KA, Lau E, Kelsh M, Barnston A. Weather changes associated with hospitalizations for cardiovascular diseases and stroke in California, 1983-1998. Int J Biometeorol 2004; 49(1):48-58.

35. Wu PC, Lin CY, Lung SC, Guo HR, Chou CH, $\mathrm{Su}$ HJ. Cardiovascular mortality during heat and cold events: determinants of regional vulnerability in Taiwan. Occup Environ Med 2011; 68(7):525-30.

36. Lim YH, Hong YC, Kim H. Effects of diurnal temperature range on cardiovascular and respiratory hospital admissions in Korea. Sci Total Environ 2012; 417-418:55-60.

37. Linares C, Díaz J. Impact of high temperatures on hospital admissions: comparative analysis with previous studies about mortality (Madrid). Eur J Public Health 2008; 18(3):317-22.

38. Hajat S, Kovats RS, Lachowycz K. Heatrelated and cold-related deaths in England and Wales: who is at risk? Occup Environ Med 2007; 64(2):93-100

39. Schwartz J, Samet JM, Patz JA. Hospital admissions for heart disease: the effects of temperature and humidity. Epidemiology 2004; 15(6):755-61.

40. Basu R, Ostro BD. A multicounty analysis identifying the populations vulnerable to mortality associated with high ambient temperature in California. Am J Epidemiol 2008; 168(6):632-7. 
41. Johnson H, Kovats R, McGregor G, Stedman J, Gibbs M, Walton H. The impact of the 2003 heat wave on daily mortality in England and Wales and the use of rapid weekly mortality estimates. Euro Surveill 2005; 10(7):168-71.
42. Pirard P, Vandentorren S, Pascal M, Laaidi K, Le Tertre A, Cassadou S, et al. Summary of the mortality impact assessment of the 2003 heat wave in France. Euro surveill 2005; 10(7):1536. 